\title{
Diversity in technology competition: the link between platforms and sociotechnical transitions
}

\begin{abstract}
There is an urgent need for a fast transition to a low-carbon economy, which will involve behavioural change and new technologies. This paper focuses on the technological dimension of the transition. Low-carbon technologies usually have a modular architecture that utilize standards to enable interfacing of components. These standards contribute to transition inertia. An important question addressed in this article is whether maintaining technological diversity can help overcome inertia. This requires keeping options open and foregoing returns to scale. It is a trade-off which has technological as well as spatial dimensions which are important because different geographical areas may provide institutional or other advantages to the emergence of distinct technologies. In order to explore this, the platform competition and transitions literature are reviewed, links between them are established, and a system dynamics model is developed where multiple new technologies compete with an incumbent. It is used to answer two questions: Will a larger portfolio accelerate or delay a transition to a new technology, and under which conditions will such an acceleration occur? does spatial differentiation matter to the outcome? The model results show that technological diversity and spatial differentiation matter for the speed of transitions. The challenge is to create a level competitive field for all technologies accounting for the distinct institutional advantages their spatial differentiation may provide. This opens a range of future research directions.
\end{abstract}

\section{Highlights:}

- I develop a model of technology evolution

- It describes competition of incumbent and new technologies

- It represents technological diversity and spatial differentiation

- It studies time to realize a full transition to new technologies

- Transition time increases with the number of technologies, and spatial dispersion

\section{Keywords:}

Socio-technical transition, niche heterogeneity, platforms, standards, system dynamics

\section{Introduction}

Our society needs to make a rapid transition away from the current fossil-fuel dominated 
economy towards renewable energy sources such as biofuels, solar and wind, and as a result considerably increase the energy efficiency of all processes. An effective solution requires technical, organizational, economic, institutional, social-cultural and political changes. Such pervasive system change is referred to as a socio-technical transition to sustainability [1-3]. For example, the electrification of the transport sector is one of several solutions put forward to address the issues associated with growth in travel demand, and the associated greenhouse gas emissions and oil demand at a global scale [4,5].

Transitions initiate when new technologies and related practices are introduced and improved, rendering them sufficiently competitive to compete with incumbent technologies [6,7]. New technologies may arise in different socio-technical systems and then speciate from one nichedomain of application to another, thus increasing the variety of competing technologies $[3,8]$. Spatial considerations are relevant as supporting actor networks arise in particular geographical locales where often specific or even unique conditions apply $[9,10]$.

New technologies introduced in a system have a higher chance of succeeding in protected niches because they enable learning and network development $[11,12]$. This allows the exploration of several technological trajectories or promising options in parallel [11]. The example from the transport system is the range of hybrid, plug-in hybrid, electric, hydrogen, and biofuel vehicles available for public or private transport $[13,14]$. The increasing number and diversity of firms becoming involved in an emerging new technological trajectory increases technology competition, and this in turn stimulates innovation and development [15]. Organizational and technological diversity is critical to the emergence and development of new technologies, including renewable energy technologies, and large system change [16-20].

It is argued that greater technological diversity catalyzes technological development and increases the potential for technology recombination [21]. Diversity can break the lock-in of established technologies. They have a competitive advantage arising from self-reinforcing increasing returns to scale which comes from demand and supply factors such as economies of scale in production, compatibility with complementary technologies, standardization, learning effects, and network externalities [22,23]. Diversity enables higher system flexibility by keeping multiple options open, which increases the likelihood of finding good technical or organizational solutions in the face of high uncertainty about long-term economic, political and social conditions [24]. However, maintaining diversity comes at the cost of fragmented market shares of technologies and low increasing returns to adoption [21].

This is where a policy dilemma for socio-technical change arises [7,25]: maintain high diversity of new technology solutions in niches, or maintain a lower diversity to rapidly achieve 
increasing returns to scale. The first option involves supporting a high diversity of expensive but promising new technologies in niches. This option facilitates learning and avoids suboptimal solutions. The scale-intensive option involves supporting a lower diversity of technologies. This option may enable relatively few fast maturing new technologies to compete with, and replace the older technologies.

Wide diversity may hamper scaling up as it fragments resources and impedes rapid innovation of the important alternatives. In addition, it increases the uncertainty about candidate technological solutions which prevents investors from fully committing to them. Low diversity can lead to an early lock-in in a suboptimal technology. Thus, the choice of niche maintaining or scale-intensive strategies presents a serious dilemma for policy making.

The competition between old and new technologies is characterized by two selection processes [26]: the replacement of established technologies by emerging ones, and the rivalry between alternative new technologies. An illustrative example is the urban transport system. In early $20^{\text {th }}$ century, it went through a transition from horse drawn carriages to cars [27]. It involved several technologies: bicycles, electric trams, electric cars, gasoline and steam cars. All of them competed in separate niches and distinct locales, and against the dominant technology of horse drawn carriages.

In the following decades the current urban transport system will undergo a new transition to low-carbon transport modes [28,29]. This transition is used as a motivating case throughout the paper and relevant literature is reviewed where appropriate. The transition may involve new conceptions of mobility, more sustainable travel patterns, and new forms of spatial planning, and new ensembles of low-carbon technologies like electric vehicles (EVs) [30]. The California Zero Emissions Vehicle mandate sparked an interest in EVs during the 1990s, and several manufacturers developed production models [31]. Its momentum was cut after the court amendment in 2003, but it did pave the way for hybrid electric vehicles and other low emission technologies [32].

At present, the dominant technology is still the internal combustion engine (ICE). A range of alternative technologies is developing, and some have entered the market, including plug-in hybrid and electric vehicles (EV) [13,14,33-35]. Most established carmakers have developed a range of alternative fuel vehicles, along with diversifying firms and startups like Tesla developed higher performance cars $[14,36]$. These technologies are not stand alone products. They are technology platforms, i.e. modular technology architectures requiring complementary products and services for their operation [37-39].

This platform architecture raises a number of issues for the transition of the transport system [40]: renewable energy integration, EV participation in electricity markets, standardisation of 
battery types, vehicle to electric grid connection and scheduling technologies, disposal and recycling of batteries, and the specifications regarding cables and plugs for recharging. Several competing technical standards, for vehicle to grid and vehicle to vehicle interfacing have been developed reflecting a local context (US, Europe and Japan) [4,41-43]. Due to different institutional advantages that distinct geographical areas offer, it is possible that the diversity of existing and future standards and platforms remain locked in niches and do not scale up, resulting in a fragmented rather than a winner takes all outcome [44,45].

The automotive industry is just one industry where technologies have a platform architecture [46]. Other technologies have a platform architecture and face challenges of similar nature e.g. telecommunications [47], computer software [48], and solar energy [20]. All of these are instrumental in implementing cleaner production processes. Thus, it is worth revisiting the dilemma stated earlier of diversity versus achieving increasing returns to scale, but from a platform competition perspective [38,49].

Technology competition in niches is an evolutionary process. Therefore, its study requires an evolutionary perspective. The present article develops an evolutionary model of technology diffusion using system dynamics [50]. The model takes into account spatial differentiation [9,10] and technology lifecycle considerations [51] in answering the question: Does the required time to transition diminish with a larger number of platform technologies? Moreover, does time diminish when different platforms are favoured in different geographical locales?

Several evolutionary models of technology adoption explore the effect of user preference heterogeneity using a variety of modelling approaches [52,53]: diffusion models with increasing returns [54-58], co-evolutionary models of users and producers [59-61], and extensions of the Nelson and Winter model [62]. Other kinds of modelling approaches have also been applied to sociotechnical transitions [63-66].

This paper builds upon the work of Loch and Huberman [67] because it offers a useful, relatively parsimonious evolutionary model where an incumbent and a new technology compete with repeated user choice, externality benefits, and learning by doing technology improvement. Their study explores the conditions under which the candidate technology replaces the incumbent. In this paper, the model is adapted to a platform setting and extended to increase its realism using: (i) a range of competing technologies rather than just one, (ii) spatial differentiation and associated unique conditions, and (iii) dynamic performance ceilings for competing technologies to account for learning.

The present paper reviews relevant parts of the sociotechnical transition and platform competition literatures, and develops a simulation model with which to address this dilemma. The 
paper makes three contributions. It clarifies the conceptual link between platforms and technology standards, and their relevance for transition research. It explores the dilemmas discussed above through the use of a simulation model that combines technology performance competition and spatial considerations. It replicates and extends an existing model in the literature. The model is used to explore how the number and variety of competing platforms can potentially delay scaling up processes, and result in spatially fragmented outcomes.

The paper is structured as follows. Section 2 reviews the technology platform literature and establishes its relevance for studying transitions to a low-carbon economy. Section 3 presents the model. Section 4 discusses simulation results. Section 5 concludes the paper.

\section{Theoretical Basis}

This section provides the conceptual basis upon which the proposed model presented in section 3 is based. This is done in three parts. Section 2.1 reviews the link of platforms and standards to sociotechnical systems and transitions. This is the starting point for section 2.2 to consider sociotechnical niches as places where new platforms develop and compete against established platforms. Finally, section 2.3 discusses the five essential factors which influence platform competition. These factors are then integrated into a model in section 3.

\subsection{A review of the links between platforms, standards and socio-technical transitions}

Technology platforms research spans engineering design and economics perspectives [39]. Gawer and Cusumano [68] define platforms as: "products, services, or technologies developed by one or more firms, which serve as foundations upon which a larger number of firms can build further complementary innovations and potentially generate network effects." In other words, platforms are the core of modular technological architectures. Use of such modules in different platforms requires the existence of standards i.e. the specifications to which products and processes must conform in order to interface with platforms [69]. There are six points of overlap between transition research and platforms competition research.

First, in the Multi-Level Perspective on sociotechnical transitions, standards are part of sociotechnical regimes [6,70,71]. Standards enable complementarities between technological components, innovations and sub-systems of technological architectures [72]. In this way, they contribute to socio-technical system inertia because they reinforce the lock in of particular technological architectures or platforms.

Second, standards being parts of sociotechnical regimes implies that platforms should be considered as well because there can be no separate demand for individual components without a 
core platform system. Thus, a platform is a technological artefact that binds a socio-technical system together. Platforms are thus expected to play a fundamental role in contemporary transitions and this is one of the many differences with past historical transitions [73-77].

For example, automotive and electricity industry actors, along with dedicated standardization bodies and developers of charging equipment, coalesced around DC and AC charging solutions for EVs [78]. A growing literature on the development of EVs has explored a number of core issues [34,79-81]: (i) the basic types of these vehicles and their technical characteristics (fuel economy and $\mathrm{CO}_{2}$ emissions), (ii) the advantages and disadvantages of hybrid electric vehicles, plug-in electric, and battery vehicles, (iii) vehicle technologies and relevant charging mechanisms, and (iv) the benefits and challenges of vehicle to grid technology, ways to overcome them, and the interaction with renewable energy sources.

Third, in the case of platforms and sociotechnical system transitions actor expectations are critical. In transitions, niches are places where actors coalesce to develop networks, learn about technologies, and articulate their expectations [7,11,82]. Articulation of expectations is also crucial in platform competition and can confer a decisive advantage that can lead to platform dominance $[48,83,84]$. The role of expectations has already been explored in the transition to alternative fuel vehicles $[85,86]$.

Fourth, sociotechnical analyses focus on the role of sociotechnical system incumbents and entrants, and how their potential competition or synergies can bring about or stifle a transition [3,6,87]. The platform competition literature addresses the same subject under the market entry and First Mover Advantage ideas. It aims to see under which conditions incumbents can maintain the status quo and FMA under new entrants competition, or whether new entrants can upstage their FMA [44,45,88-94].

Fifth, business models are part of platform competition research. They are used to explain the advantage of early movers but also the success of late entrants [95]. The role of business models is also explored in the context of sociotechnical transitions and sustainable innovation. A change of business models seems to be fundamental to getting the current sociotechnical systems out of their state of lock in $[96,97]$. There is some obvious middle ground between the two literature streams. For example, researching whether business models allow for sustainable system innovations, and how does this relate to business success and FMA.

Sixth, there is some overlap in the research outlook for platforms and socio-technical transitions. Platform competition research is shifting towards multi-level platform innovation ecosystems [68,98-100]. This multi-level research outlook could well inform the Multi-Level Perspective of transition research and vice versa [6]. There is substantial potential for integrating 
the two literature streams by developing middle-range theories that provide a satisficing trade-off between the criteria of good theory: accuracy of representation, generality, and parsimony $[6,100,101]$.

The discussion above points to the potential for conceptual integration between platform and transition research frameworks. A more detailed reviews about platforms, competition strategies, and the emerging research agenda on network effects, leveraging complementor dynamics for competitive advantage is provided in [90,102-105]. A complete discussion is beyond the scope of this paper. The preceding discussion provides enough motivation to think of niches as places for technological 99platform incubation.

\subsection{A review of niches as places for platform incubation}

This section reviews niches as places of platform incubation and development, and elaborates on core niche processes, incorporating geographic space differentiation as one of their attributes. Early on their lifecycle, new technologies are crude, imperfect, and expensive. Niches are incubation spaces that provide innovations with some form of active or passive shielding from market forces operating in a sociotechnical regime [11,106]. A sociotechnical regime consists of groups of interdepended groups of actors each with its own set of rules, the inter-regime alignment and coordination of intergroup activities that stabilize sociotechnical trajectories.

Regime internal and external market niches differ with respect to the low and high level of isolation/protection they receive [6]. A market niche is shielded from dominant socio-technical regimes through cognitive, social and spatial distances which, taken together, enable distinct selection criteria in support of the nascent technology $[9,10]$. Cognitive distance arises when regime actors do not consider the market niche as important for their products, mainly because the niche is too small and/or requires specific performance that cannot be served well by the technological variants produced within the prevailing socio-technical regime. Social distance can also be a part of niche preservation because products might serve specific social groups. Finally, spatial distance stems from the niche being located in a geographical locale where very specific conditions apply.

Active shielding might be created through specific interventions by public or private actors coming together to support a particular technology platform. Active shielding involves providing motives for the take up of particular technologies e.g. the use of alternative fuel vehicles in vehicles fleets (taxis, bus, delivery services). In contrast, passive shielding arises without direct actor involvement. Geographical locales provide a form of passive shielding where selection pressures are strong for contingent rather than strategic reasons and therefore precede any actor mobilisation 
This is illustrated in the emergence of different EV and also in the success of Danish versus US wind energy industry [9]. In both cases of active and passive shielding, niche emergence is local. Actors are involved in local networks which best suit their interests. Charging standards emerged in three distinct geographical regions (United States, Japan, and Europe), but local regime rules have led to incompatible designs [42]. An additional factor was that charging standards are at the interface between the automotive and the electricity regime [78]. The Danish success story is not just a matter of firms and entrepreneurs applying the right strategies but of specific territorial institutional advantages e.g. public-private coordination, collaboration practices and informal sharing of information [9].

Niche development helps to articulate new ways of using platforms and actor expectations, generate lessons about eco-innovation feasibility, develop and improve alternative platforms, and bring together groups of support actors [7,106]. In a market niche, technologies are repeatedly tested, modified, refined and adapted to market demands [25]. The speed, with which each experiment goes through its lifecycle, depends on the available market niche resources, and on the nature of the learning and networking processes among actors that support the technology [7,107].

Niche development has a higher chance of success when protection and experimentation is used to explore several technological trajectories or promising options in parallel [11]. Diversity is a way to stimulate innovation, permitting a broader set of alternative technology recombination paths [21]. In the case of the energy sector, supporting diversity is important in innovation for a transition to self-sustaining systems [25].

\subsection{A review of factors influencing platform market competition}

This section discusses five important factors that influence platform competition: technology learning, technological performance, supply and demand increasing returns to scale, commitment, rate of technology change $[37,39,68,88,108-110]$. The development of the model draws on this platform competition literature as discussed in section 3.

\section{Factor 1: Technology Learning}

Technology learning supports the process by which firm knowledge about action-outcome relationships and the effects of the environment on these relationships is developed [111,112]. The extent to which firms can acquire new knowledge depends on their absorptive capacity [113]. Absorptive capacity refers to both technological knowledge that supports the ability to generate technological breakthroughs, and market pioneering knowledge to support technology 
commercialization. Learning from experience can increase the chances of achieving platform dominance [114]. Failure to invest in learning can increase the likelihood of a platform being locked out of a market [88].

\section{Factor 2: Technological performance}

When a platform group can exploit its resources better than its competitors to improve the technology performance of its platform, it increases its chances of market dominance [88]. For example operational efficiency resulting from the possession of superior production capacity can contribute to achieving a technological advantage for the platform, and this can increase the chances that their platform will achieve dominance [115]. Financial resources can also allow platform supporters to acquire scarce resources, increasing the platform's technological advantage. They can also provide them with an advantage in terms of production quality and performance over their competitors.

\section{Factor 3: Supply and Demand Increasing Returns to Adoption}

Complementary products are needed to successfully commercialize platforms [111]. Their availability and interchangeability creates supply-side increasing returns to scale [116]. The existence of a wide range of complementary products and a technologically superior platform, requires a substantial and diverse network of stakeholders to support a platform in order to increase its chances of market dominance [88,109]. This is the situation EVs are facing where a network of battery and related equipment suppliers, grid operators and automotive companies are involved [117].

Demand side returns to scale arise from the utility an individual user derives from a platform as the number of its users increases [118,119]. This is influenced by the functionality of complementary products. The more users and possibilities for interconnection, the greater the user utility [83], and the higher the chance of market dominance.

Demand side increasing returns to scale driven by consumer behaviour result in path dependency $[23,120]$ which can lead to platform dominance and lock in, because of system scale economies, irreversibility of related investments and switching costs [121,122]. These effects imbue established platforms with inertia and often continuous improvements strengthen further their market share [123]. In the case of the automobile industry, such developments are evident in the improvement of internal combustion engines running on diesel or gasoline, and the slow diffusion of a variety of electricity-powered vehicles [124]. Finally, the availability of supporting infrastructure is another source of increasing returns to scale both on the supply and demand sides. 


\section{Factor 4: Commitment and Uncertainty in the market}

High uncertainty, about the technological, economic, and market technology potential may obstruct market formation and lead potential entrants away from niches [25,125]. The necessary initial experimentation to reduce the uncertainty about a new technology is a period of temporary instability for both the providers and the users $[62,126]$. Firms and customers may not be willing to take the risk of committing to one particular platform due to incomplete information and may delay their decision $[127,128]$. Another factor of uncertainty is the interpretive flexibility that platforms are imbued with and may result in favourable and unfavourable narratives about their environmental impact, job creation and boosting the economy [129].

\section{Factor 5: Rate of change and technology lifecycle}

The rate of change refers to the speed of technology and market evolution within a specific industry [44]. A high rate of change, affects technology lifecycles and reduces the motivation of users to commit to any technology [130]. The rate of change is an important factor in EVs for it also relates to overall energy consumption and $\mathrm{CO}_{2}$ emissions involved in developing and maintaining the required infrastructure [51].

These five factors, drawn from theory, are needed to develop a better understanding of platform competition. In the next section these factors are incorporated into a simulation model. The resultant model explores the effect of different factors on platform adoption.

\section{Model Development}

In this section I present a model which extends the model of Loch and Huberman [67] (LH hereafter). The LH model adopts an evolutionary approach of technology competition with boundedly rational firms i.e. they are utility driven but are unable to optimize. Firms evaluate the performance of an established platform A against a single new technology B, without being capable of evaluating perfectly its performance or anticipating which one will dominate the market. Finally, the performance of incumbent and new competing platforms improves endogenously in the model through learning and adoption processes.

The original LH model is extended by introducing: (i) continuous, incremental increase in the performance limit of established and new technologies, (ii) a range of new technology platforms, and (iii) three geographical regions (niches) with varying favourable conditions for different candidate technologies.

The core logic of the model is presented with a causal loop diagram (Figure 1) [50].The 
extended model describes a population of $N$ firms that choose between an established platform $A$ and a number of new ones $i$ (where $i=\{1 \ldots 5\}$ ). The number of technologies is used as a proxy for technology diversity. The plus sign indicates that a factor has a reinforcing effect on another, ceteris paribus, and the minus sign indicates a countering effect. Each firm chooses repeatedly whether to stay with $A$ or switch to $i$ based on evaluation of technology performance Total_Performance_G $\boldsymbol{i}_{\text {, }}$ and expectations about how it will evolve in the future. The External_Benefits arising from the network of adopters and learning by using effects, raise the level of its Basic_Performance_P . $_{-}$ Initially, it is assumed that there are no switching costs between the platforms. It is assumed that the magnitude of external benefits aggregates all increasing returns to scale.

\section{Insert Figure 1 here}

All firms evaluate performance in the same way and choose platforms based on Total_Performance_G $G_{\mathrm{i}} . G_{i}$ is subject to two influences. First, all platforms enjoy some External_Benefits [131,132]. External_Benefits aggregate increasing returns to scale complementarities and network effects discussed in section 2.3. They are assumed to vary with the market share $f_{i}=n_{i} / N$ of firms using platform $i$. This confers a technology specific external benefit $b_{i}$ for the users of platform $i$ (Figure 1).

Second, firms face some uncertainty in making a technology choice which may distort its true value (Evaluation_Uncertainty_in_Performance_i). Firms can equally over- or underestimate the actual Total_Performance_G $G_{i}$ of candidate platforms. Uncertainty in their evaluation is modelled with a random component $\xi_{i}$ that has a symmetric exponential distribution with zero mean and variance $1 / \beta^{2}$ and just as in the original LH model, its density given by:

$$
\begin{aligned}
& \xi_{i}(x)=\frac{1}{2} \beta e^{-\beta x} \text { for } x \geq 0 \\
& \xi_{i}(x)=\frac{1}{2} \beta e^{\beta x} \text { for } x<0
\end{aligned}
$$

Each firm evaluates the platforms separately and independently, so the random components $\xi_{i}$ across firms are independent and identically distributed random variables. Each user firm evaluates the performance of established platform $G_{A}(t)$ against new platform $G_{i}(t)$. Following Arthur [23] $G(t)$ is the sum of the basic technology performance $P_{i}(t)$ and the additional external benefit $b_{i}$ from every additional user of the same technology which is proportional to market share $f$. 


$$
G_{A}(t)=P_{A}(t)+f_{A}(t) b_{A} \text { and } G_{i}(t)=P_{i}(t)+f_{i}(t) b_{i}+\xi_{i}(x)
$$

Hence, while the performance $P_{A}(t)$ of established technology A is initially superior to its competitor $i$, firms are willing to experiment with new technology $i$ [62]. The performance of new technology $P_{i}(t)$ increases with use, even if firms eventually revert back to the established technology A. The uncertainty about new technology performance diminishes as knowledge about its use accumulates and it approaches its performance limit. It is assumed that uncertainty diminishes when market share increases, and information about the availability of future product versions, upgrades, complementary products and services is provided in the market [133]. This effect has been modelled in uncertainty parameter $\beta$ :

$$
\beta(t)=\beta_{O} \times\left(1-f_{i}(t)\right)
$$

where $f_{i}$ is the market share of the new technology and $\beta_{o}$ the initial technology performance uncertainty. $G_{i}(t)$ changes due to external benefits and incremental technology improvements in basic performance $P_{i}$.

\section{Technology Performance}

In the LH model there is a fixed technology performance ceiling for both established and new technologies that cannot be surpassed. The first extension to the model concerns this assumption that is not so realistic for two reasons. First, all technologies grow or diminish in size with time with corresponding improvements in functionality [134,135]. The technology improvement limits are a reflection of unit scale technology limits [136]. In the case of EVs, upscaling can involve high current capacity for fast recharging, smaller batteries, or additional functionality i.e. bidirectional transfer of electricity and information between the grid and the car.

Second, incumbent firms act through several ways to deter the entry of other firms in industries. A technology performance ceiling constitutes part of the environmental dynamics and barriers a new entrant has to face and this is not static otherwise a lot more entrants would succeed $[137,138]$. For example, in the case of passenger vehicles, automotive firms in UK and Germany have announced that they do want to develop electric vehicles in the long term, but their shortterm $\mathrm{CO}_{2}$ reduction strategies will aim on optimizing ICE vehicles [4].

These two reasons motivate an extension to the original LH model. The extended model removes the assumption of fixed technology performance ceiling by letting it increase indefinitely in time albeit with increasing levels of difficulty [139]. It is assumed that the difficulty $D$ in technology performance improvement is directly related to solving the ensuing problems of the 
technology and that it progressively increases with the number of problems solved [44]. The difficulty $D_{i}(t)$ in raising the performance ceiling $\bar{P}_{i}(t)$ of technology $i$ rises with the level of its current value according to:

$$
\begin{aligned}
& D_{i}(t)=\left(\bar{P}_{i}(t) / C_{i}\right)^{\gamma} \\
& \bar{P}_{i}(t)=\int 1 / D_{i}(t) d t
\end{aligned}
$$

Equations are motivated by analogy to the way the problem solving difficulty of scientific paradigms rises with the total number of problems solved [140]. $C_{i}$ is the intrinsic development capability of each technology which depends on infrastructure, R\&D capacity and existing knowledge, human resources and regulation. The exponent $\gamma$ influences the rate at which difficulty $D_{i}$ rises with cumulative technology development. It is assumed that $A$ and $i$ technologies do not differ in these respects and parameters $C$ and $\gamma$ are assigned same values for them.

The improvement rate of the basic technology performance $P_{i}$ depends on three factors: (i) the market share $f_{i}$ of current user firms since a larger market share encourages improvement efforts and learning by doing (their learning capability is assumed to be exogenous), (ii) the current technology performance $P_{i}$ as increasing knowledge about the technology opens up additional improvement opportunities, and (iii) the amount of performance improvement that is currently possible, which is related to the technology's inherent performance ceiling $\bar{P}_{i}$. The level of accumulated basic performance increases with the learning rate $c_{i}$ of each technology which represents the competence of its developers and complexity, and the market share $f_{i}$ of technology $i$ according to:

$$
P_{i}(t)=\int\left\{P_{i}(t)+c_{i} f_{i}(t) P_{i}(t) \frac{\left(\bar{P}_{i}(t)-P_{i}(t)\right)}{\bar{P}_{i}(t)}\right\} d t
$$

Identical values for $c$ and initial $P(t)$ are used for technologies $A$ and $i$. The adoption speed for a candidate technology $i$ depends on user expectations $E$ about how the Total_Performance_G $G_{i}(t)$ will evolve in the future:

$$
E_{i}\left(G_{i}(t)\right)=G_{i}(t)+\frac{\left(G_{i}(t)-\bar{G}_{i}(t)\right)}{\bar{G}_{i}(t) \times T_{P}} \times T_{F}
$$

Where $T_{P}$ is the time window of past technology performance improvements that users consider and $T_{F}$ is the future time about which expectations are formed. Expectations are formed based on the rate of technology learning and externalities. The core structure of the extended system dynamics model is shown below in Figure 2. Equations are listed in Appendix A. 
Insert Figure 2 here

\section{Testing and Validation}

A fundamental validation test was to reproduce the original LH model and its results (Figures 3, 4 and 5 in the original publication), since the exact code and numerical set up of their model was not available ${ }^{1}$. Tests confirmed that system resistance to switching between different states increases: (i) with the size $N$ of the adopter firm population, (ii) if the external benefits to adopters are small or heterogeneous, (iii) with the initial performance difference between established and competing platforms, (iv) if the uncertainty in evaluating the performance of the new technology $i$ is low and thus few adopters try it out, and (v) user expectations.

An exploration of the factors cited in the LH model with the present model confirms their conclusion that when system resistance to change is low, technology $i$ may be adopted without its performance exceeding that of $A$, provided that the latter's learning rate is slow. The converse is also confirmed, that technology $i$ may be adopted after its performance has exceeded the performance of $A$ because of its positive externalities. This is possible if the learning rate for technology $i$ is fast and the system's resistance is high, which a realistic transition scenario.

In addition, the extended model was tested to check its validity [50].Testing with zero network effects for the new platforms shows it is possible for a new platform to become dominant because learning by using still allows performance improvements and hence improved competitiveness. However, with zero learning by using, this is not possible. Other tests included dimensional consistency, extreme conditions where high or low values are assigned to input parameters, numerical sensitivity to simulation time step, and testing for high and low values of technology uncertainty [50].

\section{Results}

The aim of the paper was to explore how the number of competing platforms and the variety of niche conditions can potentially delay scaling up processes. For this, five versions of the model were created. For version $1 i=1$, for $2 i=2$ and so on. In each version there are three niches where competing platforms develop. This is design allows for testing the effect of number of platforms and spatial differentiation on transition time. Six setups were tested, representing an increasing differentiation of external benefits magnitude that platforms face in three niches (Table 1). Platform lifecycle was varied from 5 to 30 years ( $5 \mathrm{yr}$ step) and initial uncertainty $\beta_{\mathrm{o}}$ from 5 to 8

\footnotetext{
${ }^{1}$ The authors were contacted but it was not possible to retrieve their original program code.
} 
(step of 1). Simulation horizon was set to 100 years with a time step of 0.25 years. Each set up was simulated 100 times resulting in a total of 48000 runs.

\author{
Insert Table 1 Here
}

The following sections present simulation results concerning the effect of technology lifecycle, number of technologies and initial uncertainty $\beta_{o}$. The final section presents results concerning spatial differentiation between niches of the environment that technologies face.

\title{
Exploration of Technology Lifecycle and Initial Uncertainty $\beta_{o}$
}

Figure 3 shows simulation results for set up 1 to 6 (x-axis), for the five model versions with $i=1-5$ (y-axis), with $\beta_{\mathrm{o}}=5$ for $A$, and two technology lifecycles: $5 \mathrm{yr}$ and $30 \mathrm{yr}$. A transition to a new platform takes less time on average (red area) with a larger number of competing platforms and with strong external benefits (Figure 3, left). Longer lifecycles result in an increase in minimum and maximum time to transition (Figure 3, right). A striking difference exists between platforms with 5yr where having 3-4 technologies reduces transition time, and longer lifecycles (30yr) where having more than one or two competing platforms significantly increases the transition time. Higher external benefits perform better in all cases. Results with double the external benefits step in niches 1 and 2 (Table 1) produce qualitatively similar results in every case.

\section{Insert Figure 3 Here}

Since the model is stochastic the set up in Table 1 was simulated for $\beta_{\mathrm{o}}$ values ranging from 5 to 8. Simulations with values lower than 5 result in a permanent lock-in of the established platform A, and higher than 8 dilute any advantage a platform might have and result in perpetual competition. Figure 4 shows results with 5yr lifecycle and $\beta_{0}=6$ and 8 (plot with $\beta_{0}=7$ is quite similar to $\beta_{0}=8$ and $\beta_{0}=5$ is shown in Figure 3 ). Results show that favourable conditions (increased external benefits) along with uncertainty lead to lower time for platform substitution. The range of setups over which the minimum transition occurs is increased (bright red area) compared to Figure 3.

There are two dynamics playing out here. The increase in uncertainty results in candidate platforms $i$ being selected more often. This kick starts the reinforcing dynamics that improve their Total_Performance_G $(t)$ (Figure 1). At the same time increased initial uncertainty in evaluating technology performance obscures the best performing candidate technology and keeps it from 
achieving rapid diffusion, particularly with low external benefits (blue-green area). Thus there is a trade-off between minimum time to technology substitution, maintaining a large number of platforms with uncertain performance, and external benefits.

Insert Figure 4 here

The same tests were performed with 10yr, 20yr and 30yr lifecycles. Figure 5 presents results with a 20yr lifecycle and $\beta_{0}=5$ and 8 . The increase in initial uncertainty decreases the minimum time to platform substitution (red area) but it also increases the range of conditions over which platform substitution takes a long time (blue area in Figure 5, right). Results with a 10 and 30yr lifecycle are qualitatively identical and the range of time values is very close to the $20 \mathrm{yr}$ setting. The behaviour of the model is qualitatively the same for higher uncertainty values irrespective of lifecycle values.

\section{Insert Figure 5 Here}

The conclusion from Figures 3, 4, 5 is that: there is a trade-off between the objective of achieving a low transition time and allowing the maximum range of technology options in order to avoid an early system lock-in to an inferior option. The results also highlight the effect that technology lifecycle can have. With low uncertainty and 5yr lifecycle (Figure 4) a higher number of competing technologies produces a lower transition time than the case of longer lifecycles (Figure 5). Results offer the counterintuitive insight that with high initial uncertainty a lower number of candidate technologies is required, whereas with less initial uncertainty a higher number of technologies is desirable. This makes sense as low uncertainty allows the best performing technologies to stand out in the market relatively fast and scale up so, it allows exploration of a larger range of technologies. With high uncertainty, the time it takes for technology performance improvements to make a difference in market selection is longer. In contrast, conventional wisdom goes the other way around i.e. starting with many candidate technologies when there is uncertainty and then progressively as uncertainty is reduced, reduce the range of technologies [20].

The results justify the idea that there may be too many or too few competing technologies for achieving a balance between technological variety and scaling up and bringing about system wide change. If many niches are established, potential economies of scale are lost and reduce the total potential for major innovations and taking advantage of a larger market [141]. At the same time an excessive number of niches should be avoided particularly with highly uncertain platforms. 


\section{Lifecycle Effects}

An underlying assumption in the investigation so far is that the established and the candidate platforms have identical lifecycles. In reality niches for platform experimentation may be set up locally with a very short time horizon. Figure 6 shows candidate platform lifecycle versus the average time it takes to substitute an established platform with a lifecycle of 30yr. The greater the lifecycle, the shorter the time it takes for platform substitution, irrespective of the level of initial uncertainty. These results confirm the importance of long-term commitment to niche experiments.

\section{Insert Figure 6 Here}

\section{Spatial Differentiation}

Increasing the realism of the model, it is plausible to assume that some niches will be more conducive to specific technologies adoption. They may offer particular institutional advantages, pertinent to a geographical region i.e. passive niche protection [11]. Three niche configurations are explored to see whether spatial differentiation makes a difference.

Configuration (i) with identical external benefits across niches resulting from policies aiming to create a "level playing field" for all competing platforms [142] (Van den Bergh et la., 2006). Configuration (ii) with external benefits aligned in favour of one platform across niches. For example, the diffusion of alternative fuel vehicles (AFV) faces a "chicken-and-egg" problem: potential users wait for fuelling infrastructure to be put in place, and fuel providers and vehicle manufacturers will not invest in infrastructure until a critical mass of AFV users is achieved $[57,143,144]$.

However, the "chicken-and-egg" problem does not apply equally to all AFVs. More than half of US households can charge vehicles at home [145], so there is already infrastructure in place. Thus, BEVs and plug-in hybrids have an advantage across AFV niches in rural or suburban niches where homes have personal garages. Configuration (ii) may also apply in urban areas where car sharing schemes can utilize public access charging points or designated on-street parking, making charging accessible where home charging is impossible. In contrast, provision of dedicated refuelling infrastructure for hydrogen fuel cell vehicles appears to be essential $[53,146]$.

Configuration (iii) represents a situation where external benefits vary for different platforms across niches. All AFVs complement each other in the transition towards low emission vehicles. $\mathrm{BEV}$, PHEV, and fuel cell vehicles (FCV) are all benefitting from advances in electric drive technology (batteries, electric engines, control systems etc.) as well as from policies for electric 
mobility, related infrastructure, low emissions standards, and higher oil prices. The differentiating factors between them result from targeted policies that aim to develop platforms for specific niches and/or a combination of passive shielding arising from the local characteristics of the niches.

The high population density in urban areas allows high capacity utilization of transport infrastructure, and increases cost attractiveness of investments in public transport BEV [147]. However, in suburban areas the implementation of mass transit systems is more expensive [148]. Thus, from a cost point of view, BEVs seem to be better suited to vehicle fleets (taxis, postal delivery, city distribution, organised car sharing) and PHEV and FCV more used by individual consumers and car rental companies driving longer distances [29].

There is also spatial variability in the social benefits that AFVs produce which would reinforce the need for targeted favourable institutional conditions for one type of vehicle over others. Factors driving such differentiation include [149]: (i) the efficiency, emissions, and accessibility of the electric grid used for vehicle charging, (ii) the location and amount of vehicle miles travelled with BEV or PHEV that displaces miles travelled with gasoline, and (iii) the mix of electricity production used in a region [5,35]. Since vehicle emissions tend to occur closer to urban areas compared to electric power plant emissions, there are significant social benefits of $\mathrm{BEV}$ and PHEV use in niches aiming to relieve traffic-congested metropolitan areas.

Three possible comparisons are possible between configurations (i) and (ii), (i) and (iii), (ii) and (iii). The difference between (i) and (ii) was explored by differentiating the external benefits for the candidate technologies and comparing with the standard case of uniform external benefits (Table 2). A lifecycle of 30yr for technologies $A$ and $i$ was used and each set up was simulated 100 times. Each was tested with initial uncertainty $\beta_{o}=5-8$, with $i=2-5$ candidate technologies resulting in total of 58000 runs for 3 configuration comparisons. Initial testing indicated that 100 runs were not sufficient for statistical testing purposes and all of the tests were repeated with 200 and 300 runs. Results using 300 runs are shown in Tables 1, 2, 3, 4 (Appendix B).

\section{Insert Table 2 Here}

Results show that there is a statistically significant difference (t-test) between configurations (i) and (ii) (Table 1 in Appendix B). Technology substitution takes more time in settings where some geographic locales are less conducive to niche take off, compared to a case where candidate technologies develop under uniform and strong favourable conditions. These results show that support for one technology through policy i.e. picking early winners or support arising out passive protection because some niches are naturally more conducive to the development of certain 
platforms, is less effective than providing the same high level of support to all platforms across all niches.

In order to compare configurations (i) and (iii), configuration (ii) in Table 2 was modified so that external benefits favoured a different platform in each of the three niches i.e. platform 1 in niche 1, platform 2 in 2 and so on. In the case of two candidate platforms the model was set up with two niches instead of three. The simulation results were compared with t-tests and results show a significant difference in time (Table 2 in Appendix B). The difference in the performance of candidate platforms brought about by varying external benefits does not result in the required rate of improvement for any of them. In a sense in configuration (iii) the established platform A "sails away" for more time.

Finally, a comparison is made between configurations (ii) and (iii). The results show no statistically significant difference between them. Both though have significant differences with respect to configuration (i) where policies create a level playing field for all candidate platforms and this results in a quicker transition to new platforms.

The complementary case was also explored, where a uniform configuration was tested against differentiated ones with higher magnitude external benefits. The aim was to see whether it is better to have higher external benefits even if this means that there is an uneven support for technologies in different niches in situations where policies cannot be used to create a level playing field. Table 2 was modified as shown in Table 3.

\section{Insert Table 3 Here}

A similar series of t-tests produced the results summarised in Table 3 (Appendix B) which show that there is a statistically significant difference between configurations (i) and (v) i.e. it is better to provide increased support even for some technologies rather than providing a low level of support for all technologies.

Configuration (v) is altered to create configuration (vi) in order to reflect the same spatial differentiation with respect to external benefits as configuration (iii). This is again compared to configuration (i) and results again show that there is a statistically significant difference between the two configurations (Table 4 in Appendix B).

In summary, Tables 3, 4, 6 and 7 indicate that:

- Transition time is longer in the case where one niche technology enjoys externality benefits of high magnitude and others less so, versus a case where externality benefits are of equally high magnitude across all technologies (Figure 7, top). 
- Transition time is longer in the case where all niche technologies enjoy externality benefits of equal magnitude, versus a case where one of them enjoys substantially higher externality benefits (Figure 7, bottom).

\section{Insert Figure 7 Here}

\section{Discussion}

Results show that the number of competing technologies, the conditions resulting from geographically bound institutional advantages and/or policies, the uncertainty in technology performance evaluation and the technology lifecycle make a difference. Transition time increases with a large number of competing technologies and it is even longer when they are spatially dispersed in places that favour different technologies. Results offer the counterintuitive insight that with high initial uncertainty a lower number of candidate technologies is required than a case of less uncertainty where a wider range of technologies is desirable. Conventional wisdom goes the other way around i.e. starting with many candidate technologies and then progressively as uncertainty is reduced, the range of technologies is reduced.

Simulation results show that there is a trade-off between high initial uncertainty, maintaining a large initial number of competing platforms and reducing transition time. While increased initial uncertainty ( $\beta_{o}$ values) reduces the time to technology substitution overall, the minimum time in most cases is not achieved by having the maximum number of platforms compete. As technology matures and related uncertainty is inevitably reduced, high technological variety becomes counterproductive to technology substitution and thus adds inertia to systems that need technology change towards low carbon trajectories.

Results also show that if established and candidate platforms have different lifecycles e.g $30 \mathrm{yr}$ and 10yr, then the latter have substantially lower chances of becoming adopted. Small lifecycles result in frequent switching between technologies something that prevents commitment to one, and the earlier emergence of those with higher performance. Commitment to candidate platforms must be maintained for as long as those intended to replace. This will set in motion the selfreinforcing processes required for candidate platforms with the capacity to significantly impact the system.

The insights regarding spatial differentiation confirm that local context is important and should be taken into consideration in all future transition modelling and simulation work as different niches provide different opportunities for technology development. Ideally, a level competitive field should be created where all technologies receive equally strong support, accounting for their spatial dispersion and the varying institutional advantages it confers. However, 
it is unlikely that this will be possible everywhere, hence technology development and platform replacement will take longer.

The results point to some implications for firms and technology policy and future research directions. First, maintaining a diverse portfolio of technology options is important. Supporting early winners may result in a faster transition but can also lock in the system into an inferior solution. Prolonged periods of market competition inevitably delay the transition to a new system state. Second, incumbent and candidate technologies were conceptualized as competing in the model. However, collaboration in the automotive sector and elsewhere is also possible and is worth exploring [150]. For example, direct involvement of incumbent firms through policies for exploring use of hybrid vehicles in public transport niches seems inevitable due to the nature of these capital goods. An interesting research direction, given the technological and institutional diversity, is what is the appropriate policy mix for avoiding excessive inertia. When should competition and when should collaboration be facilitated and incentivized? A concomitant issue relates to the fact that in most cases a series of new technologies is introduced in niches gradually rather than simultaneously as in the model. Thus, future research could explore how should the policy mix be adapted in time to account for this.

Third, the non-emergence of a single dominant platform may not be detrimental to the potential for transitions. A variety of platforms can disrupt different parts of the system in a decentralized way and cumulatively make it crumble rather than having a dominant new platform. This is also an issue for future research for example in the transport system with a mix of substitutes for ICE cars, each perhaps starting with different initial uncertainty.

Finally, another issue for future work is the role of the technology ceiling. Cursory simulation runs indicate that the rate at which $\mathrm{R} \& \mathrm{D}$ raises the technology ceiling both for the established and the candidate platforms matters for the time to technology substitution.

\section{Conclusions}

This paper investigated the dilemma of developing and maintaining a diverse range of technologies versus the need for rapid scale up in order to reduce the time it takes to have a wide impact on present day carbon intensive systems. Technological diversity keeps options open and allows for spillovers, but may also mean foregoing returns to scale thus delaying transitions that are urgently needed. This dilemma has a technological and a concomitant spatial element, as different geographical locales may favour the development of different technologies.

A model of multiple technologies competing with an established system technology was developed to explore whether the required time to transition diminishes with a larger number of 
platform technologies, and whether time diminishes when different platforms are favoured in different geographical locales. The evolutionary system dynamics model developed in this paper extents prior work [67] in three ways: (i) it allows for a range of competing technologies rather than just one, (ii) it integrates spatial differentiation and associated unique conditions, and (iii) it includes dynamic performance ceilings for competing technologies to account for learning.

Results indicate that maintaining a particular degree of technological diversity is desirable but there is a threshold beyond which diversity will adversely affect technology market scale. Ideally all technologies should face an equally favourable context so that the best will emerge through selection processes. Nevertheless, the spatial variation arising from specific climatic, industrial, knowledge, population density conditions provides opportunities for simultaneously developing returns to scale and reaping some diversity benefits.

The present work highlights the importance of considering the level of technological diversity in designing policy along with other relevant criteria of efficiency, sustainability, energy security, and affordability. Diversity affects the effectiveness of policies as well as their robustness against the inherent uncertainty about technological and market developments. The take away message though is that more diversity is not always better. It may also the case that diversity may need to be actively managed temporally. Policy makers could try to coordinate the specialization of particular geographical areas to specific technologies and direct them to attain appropriate scale in order that technologies receive increased external benefits. This would potentially reduce the tension between benefits arising from diversity and increasing returns to scale.

\section{References}

[1] Elzen, B., Geels, F.W., Green K. System Innovation and the Transition to Sustainability: Theory, Evidence and Policy. Edward Elgar, Cheltenham.; 2004.

[2] Markard, J.., Raven, R., Truffer B. Sustainability transitions: An emerging field of research and its prospects. Res Policy 2012;41:955-67.

[3] Papachristos, G., Sofianos, A., Adamides E. System interactions in socio-technical transitions: Extending the Multi-Level Perspective. Environ Innov Soc Transitions 2013;7:53-69.

[4] Steinhilber, S., Wells, P., Thankappan S. Socio-technical inertia: Understanding the barriers to electric vehicles. Energy Policy 2013;60:531-9.

[5] Richardson DB. Electric vehicles and the electric grid: A review of modeling approaches, impacts, and renewable energy integration. Renew Sustain Energy Rev 2013;19:247-54.

[6] Geels, F.W, Schot J. Typology of sociotechnical transition pathways. Res Policy 2007;36:399-417.

[7] Schot, J., Geels FW. Strategic niche management and sustainable innovation journeys: theory, findings, research agenda, and policy. Technol Anal Strateg Manag 2008;20:53754.

[8] Levinthal DA. The slow pace of rapid technological change: Gradualism and punctuation in technological change. Ind Corp Chang 1998;7:217-47. 
[9] Coenen, L., Bennenworth, P., Truffer B. Toward a spatial perspective on sustainability transitions. Res Policy 2012;41:968-79.

[10] Bridge, G., Bouzarovski, S., Bradshaw, M., Eyre N. Geographies of energy transition: space, place and the low-carbon economy. Energy Policy 2013;53:331-40.

[11] Smith, A., Raven R. What is protective space? reconsidering niches in transitions to sustainability. Res Policy 2012;41:1025-36.

[12] Schot, J., Geels FW. Niches in evolutionary theories of technical change. J Evol Econ 2007; 17:605-22.

[13] Oltra, V., Saint Jean M. Variety of technological trajectories in low emission vehicles (LEVs): A patent data analysis. J Clean Prod 2009; 17:201-13.

[14] Sierzchula, W., Bakker, S., Maat, K., van Wee B. Technological diversity of emerging ecoinnovations: a case study of the automobile industry. J Clean Prod 2012;37:211-20.

[15] Utterback, J.M., Suárez FF. Innovation, competition, and industry structure. Res Policy 1993;22:1-21.

[16] Faber, A., Frenken K. Models in evolutionary economics and environmental policy: towards an evolutionary environmental economics. Technol Forecast Soc Chang 2009;76:462-70.

[17] Carrillo-Hermosilla. J., del Río, P., Könnölä T. Diversity of eco-innovations: reflections from selected case studies. J Clean Prod 2010;18:1073-83.

[18] Cooke, H., Keppo, I., Wolf S. Diversity in theory and practice: a review with application to the evolution of renewable energy generation in the UK. Energy Policy 2013;61:88-95.

[19] van Rijnsoever, F.J., van den Berg, J.C.J.M., Koch, J., Hekkert MP. Smart innovation policy: how network position and project composition affect the diversity of an emerging technology. Res Policy 2014;44:1094-107.

[20] Lacerda, S.J., van den Bergh JCJM. Diversity in solar photovoltaic energy: Implications for innovation and policy. Renew Sustain Energy Rev 2016;54:331-40.

[21] van den Bergh JCJM. Optimal diversity: Increasing returns versus recombinant innovation. J Econ Behav Organ 2008;68:565-80.

[22] David PA. Clio and the economics of QWERTY. Am Econ Rev 1985;75:332-7.

[23] Arthur, W.B. Competing technologies, increasing returns, and lock-in by historical events. Econ J 1989;99:116-31.

[24] Stirling A. Multicriteria diversity analysis. Energy Policy 2010;38:1622-34. doi:10.1016/j.enpol.2009.02.023.

[25] Jacobsson, S., Bergek A. Transforming the energy sector: the evolution of technological systems in renewable energy technology. Ind Corp Chang 2004;13:815-49.

[26] Anderson, P.; Tushman ML. Technological discontinuities and dominant designs a cyclical model of technological change. Adm Sci Q 1990;35:604-33.

[27] Geels FW. The dynamics of transitions in socio-technical systems: a multi-level analysis of the transition pathway from horse-drawn carriages to automobiles (1860-1930). Technol Anal Strateg Manag 2005;17:445-76.

[28] Cohen MJ. The future of automobile society: a socio-technical transitions perspective. Technol Anal Strateg Manag 2012;24:377-90.

[29] Dijk, M., Orsato, R.J., Kemp R. The emergence of an electric mobility trajectory. Energy Policy 2013;52:135-45.

[30] Kemp, R., Gels, F.W., Dudley, G., Lyons G. A socio-technical analysis sustainable transport. New York: Routledge; 2012.

[31] Dijk M, Yarime M. The emergence of hybrid-electric cars: Innovation path creation through co-evolution of supply and demand. Technol Forecast Soc Change 2010;77:137190.

[32] Pilkington A, Dyerson R. Innovation in disruptive regulatory environments: a patent study of electric vehicle technology development. Eur J Innov Manag 2006;9:79-91. 
[33] Offer, G.J., Howey, D., Contestabile, M., Clague, R., Brandond NP. Comparative analysis of battery electric, hydrogen fuel cell and hybrid vehicles in a future sustainable road transport system. Energy Policy 2010;38:24-9.

[34] Poullikkas A. Sustainable options for electric vehicle technologies. Renew Sustain Energy Rev 2015;41:1227-87.

[35] Yong, J.Y., Ramachandaramurthy, V.K., Tan, K.M., Mithulananthan N. A review of the state-of-the-art technologies of electric vehicle, its impacts and prospects. Renew Sustain Energy Rev 2015;49:365-85.

[36] Sierzchula W, Bakker S, Maat K, van Wee B. The competitive environment of electric vehicles: An analysis of prototype and production models. Environ Innov Soc Transitions 2012;2:49-65.

[37] Shapiro, C., Varian HR. Information Rules, a Strategic Guide to the Network Economy. Boston, MA.: Harvard Business School Press; 1999.

[38] Gawer A. Platforms, Markets and Innovation. Cheltenham, UK: Edward Elgar Publishing; 2009.

[39] Gawer A. Bridging differing perspectives on technological platforms: toward an integrative framework. Res Policy 2014;43:1239-49.

[40] Hota, A.R.,. Juvvanapudi, M., Bajpal P. Issues and solution approaches in PHEV integration to smart grid. Renew Sustain Energy Rev 2014;30:217-29.

[41] Brown, S., Pyke, D., Steenhof P. Electric vehicles: The role and importance of standards in an emerging market. Energy Policy 2010;38:3797-806.

[42] Bakker, S., Jeguijt, P., van Lente H. Niche accumulation and standardization - the case of electric vehicle recharging plugs. J Clean Prod 2015;94:155-64.

[43] Bhatti, A.R., Salam, Z., Aziz, M.J.B.A., Yee, K.P., Ashique RH. Electric vehicles charging using photovoltaics: Status and technological review. Renew Sustain Energy Rev 2016;54:34-47.

[44] Suarez FF, Lanzolla G. The role of environmental dynamics in building a first mover advantage theory. Acad Manag Rev 2007;32:377-92.

[45] Cennamo, C., Santalo J. Platform competition: Strategic trade-offs in platform markets. Strateg Manag J 2013;34:1331-50.

[46] Suarez, F.F., Utterback JM. Dominant designs and the survival of firms. Strateg Manag J 1995; 16:415-30.

[47] Majumdar, S.K., Venkataraman S. Network effects and the adoption of new technology: evidence from the U.S. telecommunications industry. Strateg Manag J 1998;19:1045-62.

[48] Schilling MA. Technological Lockout: An Integrative Model of the Economoc and Strategic Factors Driving Techology Success and Failure. Acad Manag Rev 1998;23:26784.

[49] Egyedi, T.M., Blind K. The dynamics of standards. Cheltenham, UK: Edward Elgar Publishing; 2008.

[50] Sterman JD. Business Dynamics: Systems Thinking and Modeling for a Complex World. New York: Irwin McGraw-Hill; 2000.

[51] Lucas, A., Silva, C.A., Neto RC. Life cycle analysis of energy supply infrastructure for conventional and electric vehicles. Energy Policy 2012;41:537-47.

[52] Al-Alawi, B.M., Bradley TH. Review of hybrid, plug-in hybrid, and electric vehicle market modeling studies. Renew Sustain Energy Rev 2013;21:190-203.

[53] Gnann, T., Plötz P. review of combined models for market diffusion of alternative fuel vehicles and their refuelling infrastructure. Renew Sustain Energy Rev 2015;47:783-93.

[54] Windrum, P., Birchenhall C. Is product life cycle theory a special case? Dominant designs and the emergence of market niches through coevolutionary learning. Struct Chang Econ Dyn 1998;9:109-34.

[55] Adner, R., Levinthal D. Demand heterogeneity and technological evolution: implications 
for product and process innovation. Manage Sci 2001;47:611-28.

[56] Struben, J., Sterman JD. Transition challenges for alternative fuel vehicle and transportation systems. Environ Plan B 2008;35:1070-97.

[57] Meyer, P.E., Winebrake JJ. Modeling technology diffusion of complementary goods: The case of hydrogen vehicles and refueling infrastructure. Technovation 2009;29:77-91.

[58] Zeppini, P., van den Bergh, J. 2011. Competing recombinant technologies for environmental innovation: Extending Arthur's model of lock-in. Ind Innov 2011;18:31734.

[59] Janssen, M.A., Jager W. Stimulating diffusion of green products, co-evolution between firms and consumers. J Evol Econ 2002;12:283-306.

[60] Windrum, P., Birchenhall C. Structural change in the presence of network externalities: a co-evolutionary model of technological successions. J Evol Econ 2005;15:123-48.

[61] Safarzyska, K., van den Bergh JCJM. Demand-supply coevolution with multiple increasing returns: policy analysis for unlocking and system transitions. Technol Forecast Soc Change 2010;77:297-317.

[62] Malerba, F., Nelson, R., Orsenigo, L., Winter SG. Demand, innovation, and the dynamics of market structure: the role of experimental users and diverse preferences. J Evol Econ 2007;17:371-99.

[63] Papachristos G. A system dynamics model of socio-technical regime transitions. Environ Innov Soc Transitions 2011;1:202-33/.

[64] Holtz G, Alkemade F, de Haan F, Kohler J, Trutnevyte E, Luthe T, et al. Prospects of modelling societal transitions: Position paper of an emerging community. Environ Innov Soc Transitions 2015;17:41-58.

[65] Safarzynnka K, Frenken K, van den Bergh JCJM. Evolutionary theorizing and modeling of sustainability transitions. Res Policy 2012;41:1011-24.

[66] Rao KU, Kishore VVN. A review of technology diffusion models with special reference to renewable energy technologies. Renew Sustain Energy Rev 2010;14:1070-8.

[67] Loch, C.H., Huberman BA. A punctuated equilibrium model of technology diffusion. Manage Sci 1999;54:160-77.

[68] Gawer, A., Cusumano MA. Industry platforms and ecosystem innovation. J Prod Innov Manag 2014;31:417-33.

[69] Tassey G. Standardization in technology-based markets. Res Policy 2000;29:587-602.

[70] Geels FW. From sectoral systems of innovation to socio-technical systems. Res Policy 2004;33:897-920. doi:10.1016/j.respol.2004.01.015.

[71] Geels, F.W., Hekkert, M.P., Jacobsson S. The dynamics of sustainable innovation journeys. Technol Anal Strateg Manag 2008;20:521-36.

[72] Holtz, G., Brugnach, M., Pahl-Wostl C. Specifying "regime" - A framework for defining and describing regimes in transition research. Technol Forecast Soc Change 2008; 75:62343.

[73] Fouquet R, Pearson PJG. Past and prospective energy transitions: Insights from history. Energy Policy 2012;50:1-7.

[74] Solomon BD, Krishna K. The coming sustainable energy transition : History, strategies, and outlook. Energy Policy 2011;39:7422-31. doi:10.1016/j.enpol.2011.09.009.

[75] Fouquet R. The slow search for solutions: Lessons from historical energy transitions by sector and service. Energy Policy 2010;38:6586-96.

[76] Kramer GJ, Haigh M. No quick switch to low-carbon energy. Nature 2009;462:568-9.

[77] Papachristos G. Towards multi-system sociotechnical transitions: why simulate. Technol Anal Strateg Manag 2014;26:1037-55.

[78] Bakker S, Leguijt P, van Lente H. Niche accumulation and standardization - the case of electric vehicle recharging plugs. J Clean Prod 2015;94:155-64.

doi:10.1016/j.jclepro.2015.01.069. 
[79] Mwasilu F, Justo J, Kim E-K, Do T., Jung J-W. Electric vehicles and smart grid interaction: A review on vehicle to grid and renewable energy sources integration. Renew Sustain Energy Rev 2014;34:501-16.

[80] Liu L, Kong F, Liu X, Peng Y, Wang Q. A review on electric vehicles interacting with renewable energy in smart grid. Renew Sustain Energy Rev 2015;51:648-61.

[81] Tan KM, Ramachandaramurthy VK, Yong JY. Integration of electric vehicles in smart grid: A review on vehicle to grid technologies and optimization techniques. Renew Sustain Energy Rev 2016;53.

[82] Berkhout, F. Normative expectations in systems innovation. Technol Anal Strateg Manag 2006;18:299-311.

[83] Katz ML, Shapiro C. Systems Competition and Network Effects. J Econ Perspect 1994;8:93-115. doi:10.1257/jep.8.2.93.

[84] Zhu, F., Iansiti M. Entry into platform-based markets. Strateg Manag J 2012;33:88-106.

[85] Budde B, Alkemade F, Weber KM. Expectations as a key to understanding actor strategies in the field of fuel cell and hydrogen vehicles. Technol Forecast Soc Change 2012;79:1072-83. doi:10.1016/j.techfore.2011.12.012.

[86] Bakker S, Maat K, van Wee B. Stakeholder interests, expectations and strategies regarding the development and implementation of electric vehicles: The case of the Netherlands. Transp Res Part A Gen 2014;66:52-64.

[87] Geels FW, Kern F, Fuchs G, Hinderer N, Kungl G, Mylan J, et al. The enactment of sociotechnical transition pathways: A reformulated typology and a comparative multi-level analysis of the German and UK low-carbon electricity transitions (1990-2014). Res Policy 2016;45:896-913. doi:10.1016/j.respol.2016.01.015.

[88] Schilling MA. Technological lockout: an integrative model of the economic and strategic factors driving technology success and failure. Acad Manag Rev 1998;23:267-84.

[89] Eisenmann T, Parker G, Van Alstyne MW. Strategies for two-sided markets. Harv Bus Rev 2006;84:92-101.

[90] Fosfuri A, Lanzolla G, Suarez FF. Entry-timing strategies: The road ahead. Long Range Plann 2013;46:300-11. doi:10.1016/j.lrp.2013.07.001.

[91] Lieberman MB, Montgomery DB. First Mover Advantages. Strateg Manag J 1988;9:4158.

[92] Lieberman MB, Montgomery DB. First-mover (dis) advantages: Retrospective and link with the resource-based view. Strateg Manag J 1998;1125:1111-25.

[93] Lieberman MB, Montgomery DB. Conundra and progress: Research on entry order and performance. Long Range Plann 2013;46:312-24. doi:10.1016/j.lrp.2013.06.005.

[94] Katz ML, Shapiro C, Katz, M.L., Shapiro C, Katz ML, Shapiro C. Systems competition and network effects. J Econ Perspect 1994;8:93-115. doi:10.1257/jep.8.2.93.

[95] Markides C, Sosa L. Pioneering and first mover advantages: The importance of business models. Long Range Plann 2013;46:325-34.

[96] Boons FA, Ludeke-Freunf F. Business models for sustainable innovation: state-of-the-art and steps towards a research agenda. J Clean Prod 2013;45:9-19.

[97] Boons FA, Montalvo C, Quist J, Wagner M. Sustainable innovation, business models and economic performance: an overview. J Clean Prod 2013;45:1-8.

[98] Iansiti, M., Levien R. The keystone advantage: What the new dynamics of business ecosystems mean for strategy, innovation, and sustainability. Boston, MA.: Harvard Business School Press; 2004.

[99] Tiwana, A., Konsynski, B., Bush AA. Research Commentary-Platform evolution: Coevolution of platform architecture, governance, and environmental dynamics. Inf Syst Res 2010;21:675-87.

[100] Narayanan, V.K., Chen T. Research on technology standards: Accomplishment and challenges. Res Policy 2012;41:1375-406. 
[101] Weick, K. The social psychology of organizing. Reading, MA: Addison-Wesley; 1979.

[102] Sriram S, Manchanda P, Bravo M., Chu J, Ma L, Song M, et al. Platforms: a multiplicity of research opportunities. Mark Lett 2015;26:141-52.

[103] Mcintyre DP, Subramaniam M. Strategy in Network Industries : A Review and Research Agenda. J Manage 2009;35:1494-517. doi:10.1177/0149206309346734.

[104] Mcintyre DP, Srinivasan A. Networks, Platforms, and strategy: emerging views and next stes. Strateg Manag J 2016. doi:10.1002/smj.2596.

[105] Gomez J, Lanzolla G, Maicas JP. The Role of Industry Dynamics in the Persistence of First Mover Advantages. Long Range Plann 2016;49:265-81. doi:10.1016/j.lrp.2015.12.006.

[106] Kemp R, Schot J, Hoogma R, Kemp, R., Schot, J., Hoogma R. Regime shifts to sustainability through processes of niche formation: the approach of strategic niche management. Technol Anal Strateg Manag 1998;10:175-95. doi:10.1080/09537329808524310.

[107] Freeman C. The Economics of Hope: Essays on Technical Change, Economics Growth and the Environment. London, UK: Pinter; 1992.

[108] Rochet, J-C., Tirole J. Platform Competition in Two-Sided Markets. J Eur Econ Assoc 2003;1:990-1029.

[109] Suarez FF. Battles for technological dominance: An integrative framework. Res Policy 2004;33:271-86.

[110] Suarez FF, Lanzolla G. the Role of Environmental Dynamics in Building a First Mover Advantage Theory. Acad Manag Rev 2007;32:377-92. doi:10.5465/AMR.2007.24349587.

[111] Teece DJ. Profiting from technological innovation: implications for integration, collaboration, licensing, and public policy. Res Policy 1986;15:285-305.

[112] Levinthal, D.A., March JG. The myopia of learning. Strateg Manag J 1993;14:95-112.

[113] Cohen, W.M., Levinthal DA. Absorptive capacity: a new perspective on learning and innovation. Adm Sci Q 1990;35:128-52.

[114] Klepper, S., Simons KL. Dominance by birthright: entry of prior radio producers and competitive ramifications in the U.S. television receiver industry. Strateg Manag J 2000;21:997-1016.

[115] Axelrod, R., Mitchell, W., Thomas, R.E., Bennett, D.S., Bruderer E. Coalition formation in standard-setting alliances. Manage Sci 1995;41:1493-508.

[116] Farrell, J., Saloner G. Installed base and compatibility: innovation, product preannouncements, and predation. Am Econ Rev 1986;76:940-55.

[117] Golembieskwi, B., vom Stein, N., Sick, N., Wiemhofer H-D. Identifying trends in battery technologies with regard to electric mobility: evidence from patenting activities along and across the battery value chain. J Clean Prod 2015;87:800-10.

[118] Katz, M.L., Shapiro C. Network externalities, competition and compatibility. Am Econ Rev 1985;75:424-40.

[119] Farrell, J., Saloner G. Standardization, compatibility and innovation. Rand J Econ $1985 ; 16: 70-83$.

[120] Abrahamson, E., Rosenkopf, L. Social network effects on the extent of innovation diffusion: a computer simulation. Organ Sci 1997;8:289-309.

[121] Abrahamson E. Managerial fads and fashions: the diffusion and rejection of innovations. Acad Manag Rev 1991;16:586-612.

[122] Burnham, T.A., Frels, J.K., Mahajan V. Consumer switching costs: A typology, antecedents and consequences. Acad Mark Sci 2003;31:109-26.

[123] Kemp, R., Oltra V. Research insights and challenges on eco-innovation dynamics. Ind Innov 2011;18:249-53.

[124] Dijk, M., Kemp, R., Valkering P. Incorporating social context and co-evolution in an innovation diffusion model - with an application to cleaner vehicles. J Evol Econ 
2011;23:1-35.

[125] Shrivastava P. Environmental technologies and competitive advantage. Strateg Manag J 1995; 16:183-200.

[126] Abernathy, W.J., Utterback J. Patterns of industrial innovation. Technol Rev 1978;80:407.

[127] Arthur, W. B., Lane, D.A. Information contagion. Struct Chang Econ Dyn 1993;4:81-104.

[128] Schmidt, S.K., Werle R. Co-ordinating Technology. Studies in the International Standardization of Telecommunications. Cambridge, MA.: MIT Press; 1998.

[129] Smith, A., Kern, F., Verhees B. Spaces for sustainable innovation: solar photovoltaic electricity in the UK. Technol Forecast Soc Change 2014;81:115-30.

[130] Lee, J., O’Neal, D.E., Pruett, M.W., Thomas H. Planning for dominance: a strategic perspective on the emergence of a dominant design. R\&D Manag 1995;25:3-15.

[131] Katz, M.L., Shapiro C. Technology adoption in the presence of network externalities. J Polit Econ 1986;94:822-41.

[132] Katz, M.L., Shapiro C. Systems competition and network effects. J Econ Perspect 1994;8:93-115.

[133] Padmanabhan, V., Rajiv, S., Srinivasan K. New products, upgrades, and new releases: a rationale for sequential product introduction. J Mark Res 1997;34:456-72.

[134] Nelson, R.R., Winter SG. In search of useful theory of innovation. Res Policy 1977;6:3676.

[135] Winter S. Scaling heuristics shape technology! Should economic theory take notice. Ind Corp Chang 2008;17:513-31.

[136] Wilson C. Up-scaling, formative phases, and learning in the historical diffusion of energy technologies. Energy Policy 2012;50:81-94.

[137] Caves, R.E., Porter ME. From entry to mobility barriers. Q J Econ 1977;91:241-89.

[138] Jansen, J.J.P., Van Den Bosch, F.A.J., Volberda HW. Exploratory innovation, exploitative innovation, and performance: effects of organizational antecedents and environmental moderators. Manage Sci 2006;52:1661-75.

[139] Foster R. Innovation, The Attacker's Advantage. New York.: Simon and Schuster,; 1986.

[140] Sterman, J.D., Wittenberg J. Path dependence, competition and succession in the dynamics of scientific revolution. Organ Sci 1999;10:322-41.

[141] Tisdell, C., Seidl I. Niches and economic competition: implications for economic efficiency, growth and diversity. Struct Chang Econ Dyn 2004;15:119-35.

[142] van den Bergh, J.C.J.M., Faber, A., Idenburg, A.M., Oosterhuis FH. Survival of the greenest evolutionary economics and policies for energy. Environ Sci 2006;3:57-71.

[143] Melaina, M., Bremson J. Refueling availability for alternative fuel vehicle markets: sufficient urban station coverage. Energy Policy 2008;36:3233-41.

[144] Struben J, Sterman JD. Transition challenges for alternative fuel vehicle and transportation systems. Environ Plan B Plan Des 2008;35:1070-97. doi:10.1068/b33022t.

[145] Axsen, J., Kurani KS. Interpersonal influence in the early plug-in hybrid market: observing social interactions with an exploratory multi-method approach. Transp Res D 2011;16:150-9.

[146] Greene, D.L., Park, S., Liu C. Analyzing the transition to electric drive vehicles in the U.S. Futures 2014;58:34-52.

[147] Garcia-Palmonares JC. Urban sprawl and travel to work: The case of the metropolitan area of Madrid. J Transp Geogr 2010;18:197-213.

[148] Travisi, C.M., Camagni, R., Nijkamp P. Impacts of urban sprawl and commuting: A modelling study for Italy. J Transp Geogr 2010;18:382-92.

[149] Skerlos, S.J., Winebrake JJ. Targeting plug-in hybrid electric vehicle policies to increase social benefits. Energy Policy 2010;38:705-8.

[150] Bergek, A., Berggren, C., Magnusson, T., Hobday, M. Technological discontinuities and 
the challenge for incumbent firms: Destruction, disruption or creative accumulation? Res Policy 2013;42:1210-24. 


\section{Appendix A Equation List}

\begin{tabular}{|c|c|c|c|}
\hline Name & Unit & Definition & Value \\
\hline Basic Tech Perf P1 - 5 & & 'Initial Tech Perf P1' & 1 \\
\hline Basic Tech Perf Pi - 5 & & 'Initial Tech Perf Pi' & $\{0.5,0.5,0.5,0.5,0.5\}$ \\
\hline Ceiling i Increase - 5 & $\mathrm{yr}^{\wedge}-1$ & 1/'Difficulty in further increase $-5^{\prime} / 1<<y r>>* ' S w i t c h$ Tech i Ceiling' & \\
\hline Ceiling of Technology $1-5$ & & 'Initial Technology 1 Ceiling - 5' & 5 \\
\hline Ceiling of Technology i - 5 & & 'Initial Technology i Ceiling - 5' & $\{5,5,5,5,5\}$ \\
\hline Ceilinhg 1 Increase - 5 & $\mathrm{yr}^{\wedge}-1$ & 1/'Difficulty in further increase $1-5^{\prime} / 1<<y r>>* ' S w i t c h$ Tech 1 Ceiling' & \\
\hline Denominator $\mathrm{C} \mathrm{i}$ & & 0.01 & 0.01 \\
\hline Denominator C i - 5 & & $\{0.01,0.01,0.01,0.01,0.01\}$ & $\begin{array}{l}\{0.01,0.01,0.01,0.01, \\
0.01\}\end{array}$ \\
\hline Denominator $\mathrm{C} 1$ & & 0.01 & 0.01 \\
\hline Denominator $\mathrm{C} 1-5$ & & 0.01 & 0.01 \\
\hline Difficulty in further increase -5 & & ('Ceiling of Technology i - 5'/'Denominator C i - 5')^'Exponent i - 5' & \\
\hline Difficulty in further increase $1-5$ & & ('Ceiling of Technology $1-5^{\prime} /{ }^{\prime}$ Denominator $\left.\mathrm{C} 1-5^{\prime}\right)^{\wedge^{\prime} E x p o n e n t ~} 1-5^{\prime}$ & \\
\hline Early Adopters - 5 & & 1 & 1 \\
\hline Early Adoption Rate - 5 & $\mathrm{yr}^{\wedge}-1$ & LOOKUP('Priority Allocation - 5',1)/1<<yr >> & \\
\hline Early Firms in Technology i - 5 & & $\{10,0,0,0,0,0\} / /$ index 1 is old technology & $\{10,0,0,0,0,0\}$ \\
\hline Early Return Rate - 5 & $\mathrm{yr}^{\wedge}-1$ & 'Early Firms in Technology i - 5'/FOR (i=1..6|'Tech Adoption Decision Lifecycle'[INDEX(i)]) & \\
\hline $\begin{array}{l}\text { Evaluation Random Component xhiPt1 - } \\
5\end{array}$ & & 'xhi Exp random - 5'+('Ceiling of Technology i - 5'-'Basic Tech Perf Pi - 5')/'Ceiling of Technology i - 5' & \\
\hline Exponent $1-5$ & & 1 & 1 \\
\hline Exponent i & & 0.7 & 0.7 \\
\hline Exponent i - 5 & & 'Exponent i' & $\{0.7,0.7,0.7,0.7,0.7\}$ \\
\hline External Benefit b1 & & 1 & 1 \\
\hline External Benefit Input & & 'External Benefit Range'[INDEX('RUN INDEX External Benefits')] & \\
\hline External Benefit Range & & $\begin{array}{l}\text { XLDATA("C:/Users/GP/Desktop/Future Work/MS a punctuated equilibrium model of technology diffusion/models } \\
\text { arrayed disaggregate///Output ALL tech.xls", "External Benefits", "R3C18:R12C20") }\end{array}$ & \\
\hline Externality Benefit b1 - 5 & & 1 & 1 \\
\hline Externality Benefit bi - 5 & & TRANSPOSE(FOR (i=1..5|'External Benefit Input')) & \\
\hline f1 fraction - 5 & & $\begin{array}{l}\text { ('Early Firms in Technology i - 5'[INDEX(1)] +'Mainstream Firms in Technology i - 5'[INDEX(1)]+'Late Firms in } \\
\text { Technology i - 5'[INDEX(1)]) /'Total N of Firms1 - 3' }\end{array}$ & \\
\hline
\end{tabular}


fi fraction - 5

FOR (i=Ntechnologies5| 'Early Firms in Technology i - 5'[INDEX(i+1)] +'Mainstream Firms in Technology i -

\begin{tabular}{ll}
\hline Firms in Technologies i5 & 'Early Firms in Technology i - 5'+'Mainstream Firms in Technology i - 5'+'Late Firms in \\
\hline Forecast G1 - 5 & FORECAST('Total Perf G1 - 5', 'Tech Forecasting Horizon','Tech Forecasting Horizon')
\end{tabular}

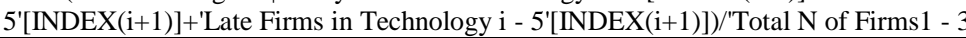

Forecast i - 5

FOR (j='Ex Benefits', i=Ntechnologies5|FORECAST(LOOKUP('Total Performance Gi - 5',j,i), 'Tech Forecasting

Initial Tech Perf P1

Initial Tech Perf P1 - 5

Initial Tech Perf Pi (Horizon', Tech Forecasting Horizon')

Initial Tech Perf Pi - 5

Initial Technology 1 Ceiling - 5

0.5

$\{0.1,0.1,0.1,0.1,0.1\}$

Initial Technology i Ceiling - 5

$\{5,5,5,5,5\}$

$\frac{0.1,0.1,0.1,0.1,0.1\}}{5}$

Input RND x - 5

FOR (i=Ntechnologies5|RANDOM(-1,1))*(1-'Switch Fixed RND') +FOR (i=Ntechnologies5|RANDOM(-

$\{5,5,5,5,5\}$

Late Adopters - 5

$\left.\left.1,1, \mathrm{i}^{*} 0.12\right)\right)^{*}$ 'Switch Fixed RND'

Late Adoption Rate - 4 1

Late Firms in Technology i - 5

$\mathrm{yr}^{\wedge}-1 \quad$ 'Priority Allocation - Copy $\left.2-4^{\prime} / 1<\langle\mathrm{yr}\rangle\right\rangle$

Late Return Rate - 5 $\{10,0,0,0,0,0\}$

Learning Rate C1

'Late Firm in

$\{10,0,0,0,0,0\}$

Learning Rate $\mathrm{Ci}$

Learning Rate Ci - 5

Technology i - 5'/FOR (i=1..6|'Tech Adoption Decision Lifecycle'[INDEX(i)]

Lifecycle Range

Lifecycleinput

Mainstream Adopters - 5

Mainstream Adoptikon Rarte - 4

Mainstream Firms in Technology i - 5

Mainstream Return Rate - 5

N RUNS External Benefits

$\{0.1,0.1,0.1,0.1,0.1\} * 1$

1

$\{5,10,15,20,25,30\}$

'Lifecycle Range'[INDEX('RUN INDEX Lifecycle')] 1

$\mathrm{yr}^{\wedge}-1 \quad$ 'Priority Allocation - Copy - 4'/1<<yr $\left.>\right\rangle$

$\{10,0,0,0,0,0\}$

$0.1,0.1,0.1,0.1,0.1\}$

N RUNS Lifecycle Range

N RUNS Parameter beta

'Mainstream Firms in Technology i - 5'/FOR (i=1..6|'Tech Adoption Decision Lifecycle'[INDEX(i)])

1000

100

1000

$\mathrm{yr}^{\wedge}-1 \quad$ 'Learning Rate C1'*'f1 fraction - 5'*'Basic Tech Perf P1 - 5'*('Ceiling of Technology 1 - 5'-'Basic Tech Perf P1

$\left.5^{\prime}\right) /$ 'Ceiling of Technology $\left.1-5^{\prime} / 1<\langle y r\rangle\right\rangle$

P1 Improvement Rate - 5

'Parameter beta range'[INDEX('RUN INDEX Parameter beta')]

Parameter beta Input

XLDATA("C:/Users/GP/Desktop/Future Work/MS a punctuated equilibrium model of technology diffusion/models

Parameter beta range

arrayed disaggregate/./Output ALL tech.xls", "Uncertainty Spread", "R3C5:R12C5") 
of Technology i - 5'[INDEX(i)]-'Basic Tech Perf Pi - 5'[INDEX(i)])/'Ceiling of Technology i -

5 '[INDEX(i)] $/ 1<<\mathrm{yr}\rangle>$

\{PRIORITYALLOC('Early Adopters - 5',\{'Early Adopters - 5','Early Adopters - 5','Early Adopters - 5','Early

Priority Allocation - 5 Adopters - 5','Early Adopters - 5','Early Adopters - 5' $\}$, \{'Forecast G1 - 5',LOOKUP('Forecast i - 5',1,1), LOOKUP('Forecast i - 5',1,2),LOOKUP('Forecast i - 5',1,3),LOOKUP('Forecast i - 5',1,4),LOOKUP('Forecast i $5 ', 1,5)\})\}$

Priority Allocation - Copy - 4

PRIORITYALLOC('Mainstream Adopters - 5', \{'Mainstream Adopters - 5', 'Mainstream Adopters - 5','Mainstrean

Adopters - 5','Mainstream Adopters - 5','Mainstream Adopters - 5','Mainstream Adopters - 5'\}, \{'Forecast G1 -

$5^{\prime}$, LOOKUP('Forecast i - 5',2,1), LOOKUP('Forecast i - 5',2,2),LOOKUP('Forecast i - 5',2,3),LOOKUP('Forecast i -

$5 ', 2,4)$, LOOKUP('Forecast i - 5',2,5)\})

\begin{tabular}{|c|c|c|c|}
\hline Priority Allocation - Copy 2 - 4 & & $\begin{array}{l}\text { PRIORITYALLOC('Late Adopters - 5',\{'Late Adopters - 5', 'Late Adopters - 5','Late Adopters - 5','Late Adopters - } \\
5^{\prime}, \text { 'Late Adopters - 5','Late Adopters - 5'\}, \{'Forecast G1 - 5',LOOKUP('Forecast i - 5',3,1), LOOKUP('Forecast i - } \\
\left.5^{\prime}, 3,2\right) \text {, LOOKUP('Forecast i - 5',3,3),LOOKUP('Forecast i - 5',3,4),LOOKUP('Forecast i - 5',3,5)\}) }\end{array}$ & \\
\hline RUN INDEX External Benefits & & INTEGER(FLOOR((RUNINDEX- 1)/'N RUNS External Benefits') + 1) //6 & 1 \\
\hline RUN INDEX Lifecycle & & INTEGER(FLOOR((RUNINDEX-1)/'N RUNS Lifecycle Range') + 1) & 1 \\
\hline RUN INDEX Parameter beta & & INTEGER(FLOOR((RUNINDEX-1)/'N RUNS Parameter beta') + 1) & 1 \\
\hline Stop Condition - 5 & & IF (RUNMAX(ARRMAX('fi fraction - 5'))>0.5,1,0) & \\
\hline Switch Fixed RND & & 0 & 0 \\
\hline Switch Tech 1 Ceiling & & 1 & 1 \\
\hline Switch Tech i Ceiling & & 1 & 1 \\
\hline Tech Adoption Decision Lifecycle & $\mathrm{yr}$ & $\{30$, Lifecycleinput,Lifecycleinput,Lifecycleinput,Lifecycleinput,Lifecycleinput $\} * 1<\langle y r\rangle>$ & $\{30,5,5,5,5,5\}$ yr \\
\hline Tech Forecasting Horizon & $\mathrm{yr}$ & $5<\langle y \mathrm{y}\rangle>$ & $5 \mathrm{yr}$ \\
\hline Time Increment - 5 & $\mathrm{yr}^{\wedge}-1$ & IF ('Stop Condition - 5'>0,0,1)/1<<yr >> & \\
\hline Time to Transition - 5 & & 0 & 0 \\
\hline Total $\mathrm{N}$ of Firms $1-3$ & & $\begin{array}{l}\text { 'Early Adopters - 5'+'Mainstream Adopters - 5'+'Late Adopters - 5'+ARRSUM('Early Firms in Technology i - 5')+ } \\
\text { ARRSUM('Mainstream Firms in Technology i - 5')+ ARRSUM('Late Firms in Technology i - 5') }\end{array}$ & \\
\hline Total Perf G1 - 5 & & 'Basic Tech Perf P1 - 5'+'f1 fraction - 5'*'Externality Benefit b1 - 5' & \\
\hline Total Performance Gi - 5 & & $\begin{array}{l}\text { FOR (i='Ex Benefits', j=Ntechnologies5| 'Basic Tech Perf Pi - 5'[INDEX(j)]+'fi fraction - } \\
\text { 5'[INDEX(j)]*LOOKUP('Externality Benefit bi - 5',i,j)+'Evaluation Random Component xhiPt1 - 5'[INDEX(j)]) }\end{array}$ & \\
\hline xhi Exp random - 5 & & $\begin{array}{l}\text { IF ('Input RND x }-5^{\prime}>=0,1 / 2 * ' P a r a m e t e r \text { beta Input'*EXP(-'Parameter beta Input'*'Input RND x - 5'), } \\
1 / 2 * ' \text { Parameter beta Input'*EXP('Parameter beta Input'*'Input RND x - 5')) }\end{array}$ & \\
\hline
\end{tabular}




\section{Appendix B Statistical Results}

Table 1 Comparison of configurations (i) and (ii)

\begin{tabular}{|c|c|c|c|c|c|}
\hline Uncertainty & set up & 2 tech & 3 tech & 4 tech & 5 tech \\
\hline \multirow{5}{*}{$\beta_{o}=5$} & 1 & $\mathrm{P}=0.013$ & $\mathrm{P}=<0.001$ & $\mathrm{P}=<0.001$ & $\mathrm{P}=<0.001$ \\
\hline & 2 & $\mathrm{P}=0.006$ & $\mathrm{P}=<0.001$ & $\mathrm{P}=<0.001$ & $\mathrm{P}=<0.001$ \\
\hline & 3 & $\mathrm{P}=0.004$ & $\mathrm{P}=0.001$ & $\mathrm{P}=<0.001$ & $\mathrm{P}=0.005$ \\
\hline & 4 & $\mathrm{P}=0.027$ & $\mathrm{P}=<0.001$ & $\mathrm{P}=<0.001$ & $\mathrm{P}=<0.001$ \\
\hline & 5 & $\mathrm{P}=0.007$ & $\mathrm{P}=0.021$ & $\mathrm{P}=<0.001$ & $\mathrm{P}=0.003$ \\
\hline \multirow{5}{*}{$\beta_{o}=6$} & 1 & $\mathrm{P}=<0.001$ & $\mathrm{P}=<0.001$ & $\mathrm{P}=<0.001$ & $\mathrm{P}=<0.001$ \\
\hline & 2 & $\mathrm{P}=0.022$ & $\mathrm{P}=<0.001$ & $\mathrm{P}=<0.001$ & $\mathrm{P}=<0.001$ \\
\hline & 3 & $\mathrm{P}=0.033$ & $\mathrm{P}=<0.001$ & $\mathrm{P}=<0.001$ & $\mathrm{P}=<0.001$ \\
\hline & 4 & $\mathrm{P}=0.036$ & $\mathrm{P}=<0.001$ & $\mathrm{P}=<0.001$ & $P=0.003$ \\
\hline & 5 & $P=0.016$ & $P=0.001$ & $P=0.047$ & $P=0.040$ \\
\hline \multirow{5}{*}{$\beta_{o}=7$} & 1 & $\mathrm{P}=0.010$ & $\mathrm{P}=<0.001$ & $\mathrm{P}=<0.001$ & $\mathrm{P}=<0.001$ \\
\hline & 2 & $\mathrm{P}=0.014$ & $\mathrm{P}=<0.001$ & $\mathrm{P}=<0.001$ & $\mathrm{P}=<0.001$ \\
\hline & 3 & $\mathrm{P}=<0.001$ & $P=0.002$ & $\mathrm{P}=<0.001$ & $\mathrm{P}=0.005$ \\
\hline & 4 & $\mathrm{P}=0.002$ & $\mathrm{P}=<0.001$ & $\mathrm{P}=<0.001$ & $\mathrm{P}=<0.001$ \\
\hline & 5 & $\mathrm{P}=<0.001$ & $\mathrm{P}=<0.001$ & $\mathrm{P}=<0.001$ & $\mathrm{P}=0.004$ \\
\hline \multirow{5}{*}{$\beta_{o}=8$} & 1 & $\mathrm{P}=0.024$ & $\mathrm{P}=<0.001$ & $\mathrm{P}=<0.001$ & $\mathrm{P}=0.003$ \\
\hline & 2 & $\mathrm{P}=0.011$ & $\mathrm{P}=0.006$ & $\mathrm{P}=<0.001$ & $\mathrm{P}=0.001$ \\
\hline & 3 & $\mathrm{P}=0.002$ & $\mathrm{P}=<0.001$ & $\mathrm{P}=<0.001$ & $\mathrm{P}=<0.001$ \\
\hline & 4 & $\mathrm{P}=<0.001$ & $\mathrm{P}=<0.001$ & $\mathrm{P}=<0.001$ & $\mathrm{P}=0.001$ \\
\hline & 5 & $P=0.002$ & $\mathrm{P}=<0.001$ & $\mathrm{P}=<0.001$ & $\mathrm{P}=0.001$ \\
\hline
\end{tabular}

Table 2 Comparison of configurations (i) and (iii).

\begin{tabular}{|c|c|c|c|c|c|}
\hline Uncertainty & set up & 2 tech & 3 tech & 4 tech & 5 tech \\
\hline \multirow{5}{*}{$\beta_{o}=5$} & 1 & $\mathrm{P}=0.013$ & $\mathrm{P}=<0.001$ & $\mathrm{P}=<0.001$ & $\mathrm{P}=<0.001$ \\
\hline & 2 & $\mathrm{P}=<0.001$ & $\mathrm{P}=0.005$ & $\mathrm{P}=<0.001$ & $P=0.030$ \\
\hline & 3 & $\mathrm{P}=0.010$ & $\mathrm{P}=<0.001$ & $\mathrm{P}=<0.001$ & $\mathrm{P}=<0.001$ \\
\hline & 4 & $\mathrm{P}=0.011$ & $\mathrm{P}=<0.001$ & $\mathrm{P}=<0.001$ & $\mathrm{P}=<0.001$ \\
\hline & 5 & $\mathrm{P}=0.011$ & $\mathrm{P}=0.005$ & $\mathrm{P}=0.008$ & $P=0.029$ \\
\hline \multirow{5}{*}{$\beta_{o}=6$} & 1 & $\mathrm{P}=<0.001$ & $\mathrm{P}=<0.001$ & $\mathrm{P}=<0.001$ & $\mathrm{P}=<0.001$ \\
\hline & 2 & $\mathrm{P}=<0.001$ & $\mathrm{P}=<0.001$ & $\mathrm{P}=<0.001$ & $\mathrm{P}=0.002$ \\
\hline & 3 & $\mathrm{P}=0.008$ & $\mathrm{P}=<0.001$ & $\mathrm{P}=<0.001$ & $\mathrm{P}=<0.001$ \\
\hline & 4 & $\mathrm{P}=0.008$ & $\mathrm{P}=<0.001$ & $\mathrm{P}=<0.001$ & $\mathrm{P}=0.011$ \\
\hline & 5 & $\mathrm{P}=0.006$ & $\mathrm{P}=0.020$ & $\mathrm{P}=<0.001$ & $\mathrm{P}=0.015$ \\
\hline \multirow{5}{*}{$\beta_{o}=7$} & 1 & $\mathrm{P}=<0.001$ & $\mathrm{P}=<0.001$ & $\mathrm{P}=<0.001$ & $\mathrm{P}=<0.001$ \\
\hline & 2 & $\mathrm{P}=<0.001$ & $\mathrm{P}=<0.001$ & $\mathrm{P}=<0.001$ & $\mathrm{P}=<0.001$ \\
\hline & 3 & $\mathrm{P}=<0.001$ & $\mathrm{P}=<0.001$ & $\mathrm{P}=<0.001$ & $\mathrm{P}=<0.001$ \\
\hline & 4 & $\mathrm{P}=0.019$ & $\mathrm{P}=<0.001$ & $\mathrm{P}=<0.001$ & $\mathrm{P}=<0.001$ \\
\hline & 5 & $\mathrm{P}=0.016$ & $\mathrm{P}=<0.001$ & $\mathrm{P}=<0.001$ & $\mathrm{P}=<0.001$ \\
\hline \multirow{5}{*}{$\beta_{o}=8$} & 1 & $\mathrm{P}=<0.001$ & $\mathrm{P}=0.003$ & $\mathrm{P}=<0.001$ & $\mathrm{P}=<0.001$ \\
\hline & 2 & $\mathrm{P}=<0.001$ & $\mathrm{P}=<0.001$ & $\mathrm{P}=<0.001$ & $\mathrm{P}=<0.001$ \\
\hline & 3 & $\mathrm{P}=<0.001$ & $P=0.012$ & $\mathrm{P}=<0.001$ & $\mathrm{P}=<0.001$ \\
\hline & 4 & $\mathrm{P}=<0.001$ & $P=0.041$ & $\mathrm{P}=<0.001$ & $P=0.009$ \\
\hline & 5 & $\mathrm{P}=0.002$ & $P=0.002$ & $\mathrm{P}=<0.001$ & $P=0.031$ \\
\hline
\end{tabular}


Table 3 Comparison of configurations (i) and (v).

\begin{tabular}{|c|c|c|c|c|c|}
\hline Uncertainty & set up & 2 tech & 3 tech & 4 tech & 5 tech \\
\hline \multirow{5}{*}{$\beta_{o}=5$} & 1 & $\mathrm{P}=<0.001$ & $\mathrm{P}=<0.001$ & $\mathrm{P}=<0.001$ & $\mathrm{P}=<0.001$ \\
\hline & 2 & $\mathrm{P}=<0.001$ & $\mathrm{P}=<0.001$ & $\mathrm{P}=<0.001$ & $\mathrm{P}=<0.001$ \\
\hline & 3 & $\mathrm{P}=<0.001$ & $\mathrm{P}=<0.001$ & $\mathrm{P}=<0.001$ & $\mathrm{P}=<0.001$ \\
\hline & 4 & $\mathrm{P}=<0.001$ & $\mathrm{P}=<0.001$ & $\mathrm{P}=<0.001$ & $\mathrm{P}=0.008$ \\
\hline & 5 & $\mathrm{P}=<0.001$ & $\mathrm{P}=<0.001$ & $\mathrm{P}=<0.001$ & $\mathrm{P}=0.027$ \\
\hline \multirow{5}{*}{$\beta_{o}=6$} & 1 & $\mathrm{P}=<0.001$ & $\mathrm{P}=<0.001$ & $\mathrm{P}=<0.001$ & $\mathrm{P}=<0.001$ \\
\hline & 2 & $\mathrm{P}=<0.001$ & $\mathrm{P}=<0.001$ & $\mathrm{P}=<0.001$ & $\mathrm{P}=<0.001$ \\
\hline & 3 & $\mathrm{P}=<0.001$ & $\mathrm{P}=<0.001$ & $\mathrm{P}=<0.001$ & $\mathrm{P}=0.002$ \\
\hline & 4 & $\mathrm{P}=<0.001$ & $\mathrm{P}=<0.001$ & $\mathrm{P}=<0.001$ & $\mathrm{P}=0.028$ \\
\hline & 5 & $\mathrm{P}=<0.001$ & $\mathrm{P}=<0.001$ & $\mathrm{P}=<0.001$ & $\mathrm{P}=0.003$ \\
\hline \multirow{5}{*}{$\beta_{o}=7$} & 1 & $\mathrm{P}=<0.001$ & $\mathrm{P}=<0.001$ & $\mathrm{P}=<0.001$ & $\mathrm{P}=<0.001$ \\
\hline & 2 & $\mathrm{P}=<0.001$ & $\mathrm{P}=<0.001$ & $\mathrm{P}=<0.001$ & $\mathrm{P}=<0.001$ \\
\hline & 3 & $\mathrm{P}=<0.001$ & $\mathrm{P}=<0.001$ & $\mathrm{P}=<0.001$ & $\mathrm{P}=<0.001$ \\
\hline & 4 & $\mathrm{P}=<0.001$ & $\mathrm{P}=<0.001$ & $\mathrm{P}=<0.001$ & $\mathrm{P}=0.004$ \\
\hline & 5 & $\mathrm{P}=<0.001$ & $\mathrm{P}=<0.001$ & $\mathrm{P}=<0.001$ & $\mathrm{P}=<0.001$ \\
\hline \multirow{5}{*}{$\beta_{o}=8$} & 1 & $\mathrm{P}=<0.001$ & $\mathrm{P}=<0.001$ & $\mathrm{P}=<0.001$ & $\mathrm{P}=<0.001$ \\
\hline & 2 & $\mathrm{P}=<0.001$ & $\mathrm{P}=<0.001$ & $\mathrm{P}=<0.001$ & $\mathrm{P}=<0.001$ \\
\hline & 3 & $\mathrm{P}=<0.001$ & $\mathrm{P}=<0.001$ & $\mathrm{P}=<0.001$ & $\mathrm{P}=<0.001$ \\
\hline & 4 & $\mathrm{P}=<0.001$ & $\mathrm{P}=<0.001$ & $\mathrm{P}=<0.001$ & $\mathrm{P}=<0.001$ \\
\hline & 5 & $\mathrm{P}=<0.001$ & $\mathrm{P}=<0.001$ & $\mathrm{P}=<0.001$ & $\mathrm{P}=<0.001$ \\
\hline
\end{tabular}

Table 4 Comparison of configurations (i) and (vi).

\begin{tabular}{|c|c|c|c|c|c|}
\hline Uncertainty & set up & 2 tech & 3 tech & 4 tech & 5 tech \\
\hline \multirow{5}{*}{$\beta_{o}=5$} & 1 & $\mathrm{P}=<0.001$ & $\mathrm{P}=<0.001$ & $\mathrm{P}=<0.001$ & $\mathrm{P}=<0.001$ \\
\hline & 2 & $\mathrm{P}=<0.001$ & $\mathrm{P}=<0.001$ & $\mathrm{P}=<0.001$ & $\mathrm{P}=<0.001$ \\
\hline & 3 & $\mathrm{P}=<0.001$ & $\mathrm{P}=<0.001$ & $\mathrm{P}=<0.001$ & $\mathrm{P}=<0.001$ \\
\hline & 4 & $\mathrm{P}=<0.001$ & $\mathrm{P}=<0.001$ & $\mathrm{P}=<0.001$ & $\mathrm{P}=0.002$ \\
\hline & 5 & $\mathrm{P}=<0.001$ & $\mathrm{P}=0.001$ & $\mathrm{P}=<0.001$ & $\mathrm{P}=0.027$ \\
\hline \multirow{5}{*}{$\beta_{o}=6$} & 1 & $\mathrm{P}=<0.001$ & $\mathrm{P}=<0.001$ & $\mathrm{P}=<0.001$ & $\mathrm{P}=<0.001$ \\
\hline & 2 & $\mathrm{P}=<0.001$ & $\mathrm{P}=<0.001$ & $\mathrm{P}=<0.001$ & $\mathrm{P}=<0.001$ \\
\hline & 3 & $\mathrm{P}=<0.001$ & $\mathrm{P}=<0.001$ & $\mathrm{P}=<0.001$ & $\mathrm{P}=<0.001$ \\
\hline & 4 & $\mathrm{P}=<0.001$ & $\mathrm{P}=<0.001$ & $\mathrm{P}=<0.001$ & $\mathrm{P}=<0.001$ \\
\hline & 5 & $\mathrm{P}=<0.001$ & $\mathrm{P}=<0.001$ & $\mathrm{P}=<0.001$ & $\mathrm{P}=<0.001$ \\
\hline \multirow{5}{*}{$\beta_{o}=7$} & 1 & $\mathrm{P}=<0.001$ & $\mathrm{P}=<0.001$ & $\mathrm{P}=<0.001$ & $\mathrm{P}=<0.001$ \\
\hline & 2 & $\mathrm{P}=<0.001$ & $\mathrm{P}=<0.001$ & $\mathrm{P}=<0.001$ & $\mathrm{P}=<0.001$ \\
\hline & 3 & $\mathrm{P}=<0.001$ & $\mathrm{P}=<0.001$ & $\mathrm{P}=<0.001$ & $\mathrm{P}=<0.001$ \\
\hline & 4 & $\mathrm{P}=<0.001$ & $\mathrm{P}=<0.001$ & $\mathrm{P}=<0.001$ & $\mathrm{P}=<0.001$ \\
\hline & 5 & $\mathrm{P}=<0.001$ & $\mathrm{P}=<0.001$ & $\mathrm{P}=<0.001$ & $\mathrm{P}=<0.001$ \\
\hline \multirow{5}{*}{$\beta_{o}=8$} & 1 & $\mathrm{P}=<0.001$ & $\mathrm{P}=<0.001$ & $\mathrm{P}=<0.001$ & $\mathrm{P}=<0.001$ \\
\hline & 2 & $\mathrm{P}=<0.001$ & $\mathrm{P}=<0.001$ & $\mathrm{P}=<0.001$ & $\mathrm{P}=<0.001$ \\
\hline & 3 & $\mathrm{P}=<0.001$ & $\mathrm{P}=<0.001$ & $\mathrm{P}=<0.001$ & $\mathrm{P}=<0.001$ \\
\hline & 4 & $\mathrm{P}=<0.001$ & $\mathrm{P}=<0.001$ & $\mathrm{P}=<0.001$ & $\mathrm{P}=<0.001$ \\
\hline & 5 & $\mathrm{P}=<0.001$ & $\mathrm{P}=<0.001$ & $\mathrm{P}=<0.001$ & $\mathrm{P}=<0.001$ \\
\hline
\end{tabular}

